\title{
Proceedings of The Society of Thoracic and Cardiovascular Surgeons of Great Britain and Ireland
}

\author{
The Annual Meeting of The Society of Thoracic and Cardiovascular Surgeons of Great Britain and
} Ireland was held on 13 and 14 October 1977 at the Royal Lancaster Hotel, London. Summaries of the papers follow:

\begin{abstract}
Membranous part of ventricular septum in Man, with particular reference to membranous defects of ventricular septum
\end{abstract}

S. P. ALLWORK and R. H. ANDERSON Interventricular communication accounts for one-fifth of all congenital cardiac anomalies, and more than three-quarters of these have been described as 'membranous'. Ventriculoatrial communication through the membranous part of the septum is, however, rare. This disparity of incidence of malformation of the two components of this structure prompted us to examine hearts aged from 15 weeks of gestation to the ninth decade of adult life.

The atrioventricular component was evident in all the hearts, but the interventricular component was rarely present in the fetuses or in the first year of life. In these hearts there was no fibrous tissue between the medial tricuspid leaflet and the muscular ventricular septum. Instead, the area occupied by the interventricular component in the adult heart was filled by the penetrating bundle and muscle. The medial tricuspid leaflet was attached to the muscle through most of its length. In adult hearts the medial tricuspid leaflet was, in every case, attached to the interventricular membranous septum by secondary chordae tendineae.

The development and adult anatomy of the whole membranous part of the ventricular septum is considered relative to defective septation of the ventricles.

Late results after primary repair of large ventricular septal defects in the first year of life

R. STANBRIDGE, R. RADLEY-SMITH, and M. YACOUB It has been our policy to perform primary repair of large ventricular septal defects in the first year of life if there is severe intractable cardiac failure, or persistent pulmonary hypertension in infants approaching 1 year of age. Twenty-six infants underwent repair; their ages were between 1 and 12 months. Eleven were under 3 months. One child died early. Twenty children have been followed up for between 1 and $6 \frac{1}{2}$ years (mean 37 months). There have been no late deaths and all children are asymptomatic. Late, postoperative cardiac catheterisation was performed in 15 patients. The pulmonary artery pressure was normal at rest, and on exercise in all. There were no residual shunts.

It is concluded that the primary repair of large ventricular septal defects in the first year of life gives good results and appears to prevent pulmonary hypertension.

\section{Current indications for cardiopulmonary conduits}

MARC DE LEVAL, ROBERT J. SZARNICKI, and JAROSLAV STARK The use of valved conduits to restore continuity between cardiac chambers and the pulmonary circulation has facilitated the repair of several congenital heart defects. We have reviewed our experience with 63 patients operated upon between January 1971 and October 1976. Based on this experience, we have outlined our current indications for the use of cardiopulmonary conduits (C-P conduits).

1. Transposition complexes (32 patients): (a) transposition of the great arteries (TGA) with ventricular septal defect (VSD) and left ventricular outflow tract obstruction (LVOTO) (Rastelli operation) and (b) TGA with intact ventricular septum + LVOTO (LV to PA conduit).

2. Establishment of right ventricle to pulmonary artery continuity in cases of single arterial trunk: (a) truncus arteriosus (15 patients) and (b) pulmonary atresia + VSD with pulmonary arteries supplied by systemic vessels (7 patients).

3. Abnormal coronary anatomy which prevents adequate relief of infundibular stenosis by patch enlargement without injury to coronary circulation (5 patients).

4. Right atrium to pulmonary artery connection for cases of single atrioventricular (A-V) valve ( 2 patients), including tricuspid atresia and some forms of primitive ventricle (Fontan operation).

5. Cases of atrioventricular discordance or primitive ventricle in which the relief of a pulmonary stenosis may injure the conduction mechanism ( 1 patient).

6. Anticipated residual pulmonary hypertension in patients with increased pulmonary arteriolar resistance after systemic to pulmonary shunt in whom relief of $D$ pulmonary stenosis would necessitate patch enlarge- 을 ment with resultant pulmonary valvular incompetence. $\mathbb{N}$

Results of surgical treatment of Wolff-Parkinson- $\mathbb{N}$ White syndrome

A. J. CAMM, G. M. REES, D. E. WARD, and R. A. J. SPURRELL Ten patients (2 female and 8 male) between 15 and 70 years with Wolff-Parkinson-White $\frac{c}{\Phi}$ (WPW) syndrome were studied preoperatively by intracardiac recording and stimulation techniques. $\square$ Two patients had left lateral atrioventricular (AV) $\bar{O}$ bundles (type $A$ pre-excitation) and 8 patients had $\vec{D}$ right-sided AV bundles (type $B$ pre-excitation) at $\frac{\rho}{\Phi}$ various sites along the AV groove. Septal bypasses $\unrhd$ were carefully excluded. Three patients had co-existing $\bar{\sigma}$ 
abnormalities, one coronary artery disease, one Ebstein's anomaly, and one aortic valve disease.

One patient was asymptomatic with respect to the WPW but had coronary artery disease requiring surgery. Five patients had atrial fibrillation with a rapid ventricular response and nine patients had rapid symptomatic re-entrant tachycardias unresponsive to medical treatment.

The surgical technique included construction of an isochrone activation map of the epicardial surface of the ventricles. An atriotomy was performed with the patient on normothermic bypass, and the atrium around the mitral or tricuspid valve ring was mapped during tachycardia or ventricular pacing. The point of earliest activation on the atrial endocardium at the junction with the annulus fibrosus was incised by diathermy. After closure of the atriotomy the ventricles were re-mapped and normal activation was observed in all patients.

During follow-up for 3 to 18 (mean 10) months there has been no recurrence of WPW tachycardia or pre-excitation.

The operation was performed without significant operative complication and has proved successful in all patients.

A rare case of transposition of the great arteries with total anomalous pulmonary venous drainage of the supracardiac type

J. F. DARK, A. RAHMAN, and D. BETON A 27-year-old man presented with dyspnoea, cyanosis, and tiredness. Investigation in his youth elsewhere had suggested truncus arteriosus, but new investigations revealed the presence of transposition of the great arteries with total anomalous pulmonary venous drainage of the supracardiac type.

Surgical repair consisted of making a communication between the pulmonary venous sinus and the back of the right atrium with completion of the inflow switch by suturing in a pericardial Mustard baffle.

Recovery was uneventful, but nine months later the patient developed a recurrence of cyanosis and dyspnoea, and further investigations showed obliteration of the channel between the superior vena cava and the left atrium and a leak around the upper end of the baffle. There was also gross tricuspid incompetence.

At a further operation the baffle was incised and patched, and a xenograft was used to replace the faulty tricuspid valve. From this he recovered well.

Tracheal compression of the aortic arch after right pneumonectomy in infancy

J. STARK, R. SZARNICKI, and M. DE LEVAL Uneventful pneumonectomy was carried out in a 10-month-old infant for a hypoplastic right lung associated with oesophageal origin of the right main bronchus. Eight months after surgery, symptoms of tracheal compression began. This compression was due to the aortic arch which was stretched across the lower trachea following the displacement of the heart to the posterior right chest after pneumonectomy. Successful relief of the airway obstruction was achieved by inserting a $20 \mathrm{~mm}$ woven Dacron graft between the ascending and descending aortae, with division of the aortic arch between the left carotid and left subclavian arteries. An aortogram performed two years after surgery confirmed good patency of the graft with normal flow through the descending aorta. The child remains well two years after surgery but continues to have a limited exercise tolerance compatible with the presence of only one lung and a mild residual tracheomalacia.

\section{Experimental and clinical experience with hypothermic} cardiac arrest

PETER ALLEN and R. T. MIYAgisima Cardiac surgeons continually search for the best way to obtain an inert, bloodless field in open cardiac operations. Selective cardiac hypothermic arrest offers, through a simple technique, both adequate myocardial preservation and excellent operating conditions.

One hundred and fifty consecutive patients are presented in whom cold arrest, with potassium solution, was used for a variety of lesions, both congenital and acquired. During arrest, which in some cases was over two hours, we continually measured myocardial septal temperatures, which frequently rose to normothermia within 25 minutes, yet our reinforcing of the cold arrest was of ten delayed another 30 minutes.

In all but four cases, cardiac resuscitation was uncomplicated, and there were no instances of prolonged low output state attributable to the hypothermic arrest.

Intraoperative and postoperative CPK isoenzyme studies plus postoperative cardiac function studies showed no myocardial damage. We have completed a series of animal experiments to determine if the hypothermic aspect of the arrest solution is indeed necessary.

Results of the various studies and our simplified technique of cold arrest will be discussed.

\section{Post-pneumonectomy empyema}

P. Goldstraw Prevention is better than cure. This maxim applies to all surgical complications, but perhaps more so to post-pneumonectomy empyema, where the morbidity of the complication of ten seriously detracts from the extension of survival achieved by pneumonectomy for carcinoma of the bronchus.

The initial steps in prevention should include obtaining as much information as possible on the problem, assessing its extent, and identifying any predisposing factors. These initial steps are difficult when studying post-pneumonectomy empyema, mainly since surgeons have always been more enthusiastic in publishing their successes than in documenting their failures. The experience of the surgeons in the Cardiothoracic Unit, Mearnskirk Hospital, Glasgow over a 12-year period is presented, along with the sparse statistics from the literature. This information is used to assess the incidence, predisposing factors, and possibly prophylactic measures for post-pneumonectomy empyema. 
There is a recurring suggestion that empyema in the post-pneumonectomy space may increase the chances of long-term survival. The facts concerning this belief are studied and found to be statistically unsound and at variance with our experience. It is believed that this possibility should not deter one from a determined prophylactic regime.

For the established failure, various treatment options are compared and recommendations made.

Incidence of postoperative infection and role of antibiotic prophylaxis in pulmonary surgery

D. K. C. COOPER A study of the nature and incidence of postoperative infection has been made in 221 consecutive patients undergoing thoracotomy for lung resection. Ninety-three per cent of the operations were performed for malignant tumours. Prophylactic systemic ampicillin and flucloxacillin (Magnapen) were administered by one of three slightly varying regimes to a total of 181 patients; the 40 remaining patients received antibiotics only when indicated by the occurrence of postoperative clinical infection.

A knowledge of the nature of the organisms cultured from the sputum (preoperatively) or from the bronchus (at operation) which were, in general, of relatively low pathogenicity, proved to be of little value in treating postoperative infections, as the postoperative organism was in nearly every case different from the one cultured previously.

There was a significantly reduced incidence of pneumonectomy space infection, postoperative pneumonia, and wound infection after pneumonectomy and lobectomy in those patients receiving prophylactic antibiotics compared with those not receiving prophylactic antibiotics.

The application of penicillin and streptomycin powder to the region of the bronchial stump at operation did not reduce the incidence of either bronchopleural fistula or pneumonectomy space infection.

There was an increased incidence of culture of Gram-negative bacteria and of Candida from the postoperative sputum of those patients receiving heavy antibiotic phophylaxis, though in no case did these organisms become a serious clinical problem.

\section{Influence of pre-ischaemic factors on post-ischaemic left ventricular function during cardiopulmonary bypass}

E. G. BUTCHART Satisfactory myocardial protection during open cardiac surgery necessitating a period of global ischaemia remains controversial. This study stresses the importance of the contractile state of the left ventricle and the arterial blood glucose immediately before a period of ischaemia. All experiments were performed on dogs subjected to 90 minutes of global ischaemia on cardiopulmonary bypass at $28^{\circ} \mathrm{C}$ with perfusion pressure maintained at $90 \mathrm{mmHg}$ before ischaemia. The maximum rate of development of left ventricular pressure $(\mathrm{LVdp} / d t)$ at constant arterial and left atrial pressures was used to measure contractility before ischaemia. In a group of 18 dogs undergoing anoxic arrest, arterial blood glucose in conjunction with the pre-ischaemic $\mathrm{LVdp} / d t$ and the time that the left ventricle continued to beat whilst anoxic (metabolic supply/demand index) were significantly predictive of the functional result following ischaemia. In two further groups of dogs with arterial blood glucose $>120 \mathrm{mg} / 100 \mathrm{ml}$, subjected to potassium cardioplegia, 'normal' pre-ischaemic LVdp/dt ( 7 dogs) was associated with a good functional result but an elevated pre-ischaemic $\mathrm{LV} d p / d t$ (6 dogs) produced severe functional impairment following ischaemia. The metabolic basis for these results and their clinical implications are discussed and conclusions are drawn concerning the optimum management of the period immediately before ischaemia during cardiopulmonary bypass.

Conservative surgery for reflux oesophagitis with stricture: a comparison between two methods

K. MOGHISSI The paper is a retrospective study of 108 cases of hiatus hernia and oesophageal stricture with particular reference to and analysis of 78 patients on whom conservative surgery was carried out.

In 34 patients (group 1) transgastric dilatation of the stricture and an Allison type operation for hiatus hernia repair was carried out. In the remaining 44 patients (group 2), a transgastric dilatation of the stricture and a Nissen type fundoplication was performed. Group 2 patients could be subdivided according to whether the fundoplication was placed in the abdomen (group 2a, 24 patients), or the chest (group 2b, 20 patients).

RESULTS

Three of the 78 patients died in hospital. In the remaining 75 patients the follow-up period is from 6 months to $6 \frac{1}{2}$ years.

Group 1

Two patients died.

Four patients needed post-operative dilatation.

Two patients have no dysphagia but experience medically manageable heartburn.

Twenty-six patients are absolutely asymptomatic.

Group 2

Sub-group $2 a$

One patient died.

One patient needed post-operative dilatation.

Twenty-two patients are asymptomatic.

Sub-group $2 b$

No hospital mortality.

All 20 patients are asymptomatic.

Our experience indicates that for oesophageal reflux stricture yielding to dilatation, operative dilatation, $\stackrel{\mathcal{S}}{+}$ and an anti-reflux operation gives satisfactory results. T A Nissen type fundoplication and crural approximation has been more successful in this series than the Allison type of operation. For high strictures, dilata- $\mathbb{D}$ tion and intrathoracic fundoplication has been entirely $\frac{Q}{\sigma}$
satisfactory. 
What makes the Nissen fundoplication operation work?

A. J. GUNNING and R. B. Marshall Despite a great amount of research and speculation, the precise mechanisms that normally prevent and control gastrooesophageal reflux are still not clearly understood. Many operations-all claiming success-have been described to prevent gastro-oseophageal reflux. Of these operations, the Nissen fundoplication is now the commonest one performed. The mechanism by which this operation succeeds has not been clarified. Most authors consider that the operation produces a new physiological sphincter.

A series of clinical studies will be reported of pre, intra, and continuing postoperative manometric studies showing that no new sphincter is formed and that the mechanism of reflux prevention in the Nissen fundoplication operation is a mechanical one.

\section{Prognosis and management of oesophageal perforations}

F. A. SANDRASAGRA, T. A. H. ENGLISH, and B. B. MILSTEIN Perforation of the oesophagus is associated with a high morbidity and mortality, and the most appropriate method of management remains controversial. This report presents our experience with 28 patients who had oesophageal perforation during a five-year period. Twenty-one followed oesophageal instrumentation, four were associated with paraoesophageal surgical procedures, and three were spontaneous. Pain, fever, or surgical emphysema following endoscopy were common modes of presentation. Plain radiographs of the chest, neck, and abdomen provided confirmatory evidence of perforation in all cases. Contrast studies of the oesophagus demonstrated the site and extent of the leak in 21 of 26 cases.

The various methods of treatment employed depended on the interval between perforation and diagnosis, the site of perforation, and the pre-existing pathology, The overall early mortality was $32 \%$. Instrumental perforations were associated with a lower mortality than spontaneous perforations or those following paraoesophageal procedures, and mortality for thoracoabdominal perforations was nearly three times that for the cervical segment. The presence of oesophageal obstruction in association with a perforation did not have an adverse effect on the outcome. The time lapse between occurrence of the perforation and surgical treatment had a profound influence on morbidity and mortality. Early closure of thoracoabdominal perforations and drainage was associated with a $25 \%$ mortality and no complications in the survivors. On the other hand, a delay of over 24 hours was associated with a high incidence of septic complications in both cervical and thoracoabdominal perforations, longer periods of drainage, and a $50 \%$ mortality in the latter group. Early surgical treatment is therefore recommended for both cervical and thoracoabdominal perforations.

\section{Unusual presentations of mediastinal fibrosis}

R. K. WALESBY and W. P. Cleland The classical picture of mediastinal fibrosis is that of non-malignant superior vena caval obstruction due to a progressive fibrosis of the mediastinum. Of six patients diagnosed with mediastinal fibrosis in the years 1970-76 at the Hammersmith and Brompton Hospitals, only two exhibited superior vena caval obstruction, and in one of these pernicious anaemia was also present. Other presentations included one with bilateral bronchostenosis, one with extensive carotid sheath sclerosis, one with recurrent laryngeal nerve paresis, and one with scattered fibrosed tumours of the mediastinum. Retroperitoneal fibrosis was not present in any patient and there were no deaths. Association with histoplasmosis, tuberculosis, and syphilis are reported but generally, as in this series, the aetiology was not found.

In five patients histological diagnostic confirmation was obtained at surgery, which comprised thoracic inlet exploration in one patient, mediastinoscopy and thoracotomy due to accidental haemorrhage in another, and primary exploratory thoracotomy in three. Malignancy was thus excluded by surgery in the first five patients and by length of history in the sixth.

Definitive procedures included pleurectomy for recurrent unilateral hydrothorax and unilateral bronchoplasty for bronchostenosis. Two patients were treated with penicillamine resulting in a dramatic regression of one lesion but no significant change in the other.

Mediastinal fibrosis is discussed from both the diffuse nature of the disease entities included in the nomenclature and the surgical and medical therapeutic aspect.

\section{Mediastinal fibrosis from paraffin wax}

R. E. FRANKS and W. P. CLELAND Paraffin wax has been used as a relatively safe agent with suitable physical characteristics for introduction into the body for various therapeutic purposes. However, reactions to it are well documented.

Reactions are known to occur locally but are also reported at sites remote from the area of introduction.

We have seen two instances of mediastinal obstruction from wax introduced into sites without direct continuity with the mediastinum. The first underwent mammoplasty and the second collapse therapy for tuberculosis, both many years previously. Having a melting point above body temperature it is thought that the wax is transported by macrophages.

The clinical details of these two patients with unpleasant symptoms of mediastinal obstruction, resulting from a therapeutic and a plastic procedure, will be shown, and the evidence for the mode of movement of the wax reviewed.

\section{United Kingdom Cardiac Surgical Register-report on pilot study}

T. A. H. ENGLish Cardiac surgery makes important demands on capital resources and skilled manpower. Both, therefore, should be used as efficiently and economically as possible. The establishment of a permanent register for cardiac surgery would permit the collection of accurate data on the volume, type, 
and distribution of work performed each year in the United Kingdom. This would help promote the rational use and future planning of cardiac surgical services and also probably improve the general standard of cardiac surgery as reflected by national mortality figures.

At the Executive Meeting of the Society of Thoracic and Cardiovascular Surgeons in January 1977 it was agreed that a pilot study should be conducted on work done during 1976. On 10 March forms based on those used for the Australian register were distributed to each of the 47 NHS hospitals in Britain and Northern Ireland in which open-heart surgery is practised. Confidentiality was respected by return of the completed forms to the secretary of the Society, who provided each unit with a code number before forwarding the anonymous data for analysis. By 15 May half the forms issued had been returned, but after further reminders 37 complete returns were received by 5 September. Of the remaining 10 units, four made no returns, three returns were incomplete, there were two refusals, and one arrived too late for analysis. The following data, therefore, reflect the combined experience of approximately $80 \%$ of the 47 NHS hospitals involved in cardiac surgery in the UK during 1976.

A total of 8927 cardiac operations (excluding pacemakers) were performed with an overall hospital mortality (death within 30 days of operation) of $10 \%$. Of 7275 open cardiac operations, 3665 were for adult valve disease, 1467 for ischaemic heart disease (with or without valve surgery), 1938 for congenital heart disease, and 205 were classified as miscellaneous.

Altogether, 2920 open single valve operations, 675 double, and 70 triple valve operations were performed with mortalities of $7 \%, 14 \%$, and $20 \%$ respectively. The mortality for isolated open aortic valve procedures $(8 \%)$ ranged from $1.4 \%$ (1 of 70 ) to $34 \%$ (12 of 36 ), and for isolated open mitral valve operations $(7 \%)$ from $0 \%$ (0 of 78 ) to $14 \%$ (14 of 99). There were 466 closed mitral valvotomies with seven deaths (mortality $1.5 \%$ ).

One thousand and eighty-three isolated coronary bypass graft operations were performed with a mortality of $5 \%$. No statistical difference existed in the mortality (given in parentheses) between 241 single grafts $(4 \%), 392$ double $(5 \%), 376$ triple $(6 \%)$, 69 quadruple $(3 \%)$, and 5 quintuple grafts $(0 \%)$. Two hundred and forty-six other operations were performed in which bypass grafts were combined with additional procedures, such as $101 \mathrm{LV}$ aneurysmectomies $(20 \%) ; 85$ AVRs $(17 \%) ; 44$ MVR repairs $(14 \%)$; and 16 miscellaneous procedures $(30 \%) ; 138$ operations for IHD were performed without associated coronary bypass grafts. These included $95 \mathrm{LV}$ aneurysmectomies (mortality $21 \%$ ) and 20 VSD repairs (mortality $35 \%$ ).

All 37 units practised some closed congenital surgery; 439 PDAs were operated on with three deaths, and 313 coarctations with 16 deaths ( 14 of these were in infants under 1 year). There were 1750 open operations in children over 1 year (mortality $9 \%$ ) and $\stackrel{\vec{F}}{+}$ 188 open operations in infants under 1 year (mortality $36 \%$ ). Only five units did more than 100 open congenital operations per year. The mortality for some of $\frac{\bar{\rho}}{\bar{c}}$ the commoner open congenital operations (children $\mathbb{\odot}$ and infants) was as follows: 443 ASDs $(1.4 \%) ; 226$ pulmonary valve operations $(4 \%) ; 112$ aortic valve ${ }^{\infty}$ operations $(7 \%) ; 274$ VSDs $(10 \%), 357$ Fallot's tet- $\overrightarrow{0}$ ralogy $(15 \%)$; and 79 Mustard operations for 'simple' TGA $(16 \%)$. Figures for the less common congenital $\vec{\omega}$ operations and the miscellaneous group of open cardiac operations were also analysed.

Two years' experience with the Lillehei Kaster:prosthetic valve

IAIN M. BECKENRIDGE Between May 1975 and Mayo 1977, 78 Lillehei Kaster pivoting disc (LKPD) valves were inserted into 67 patients, ranging in age from $\vec{T}$ 4 to 68 (mean 49 ) years. This valve, introduced clini- $\$$ cally in 1970, incorporates a free-floating disc of $\frac{O}{2}$ Pyrolite carbon in a titanium housing encircled by a Teflon fabric sewing ring. Compared with the Björk-₹ Shiley valve, the maximum disc opening angle is $\overrightarrow{0}$ greater, the area for flow behind the disc is relatively larger, and the haemodynamic performance 'in vivo' is at least equivalent. Valves are delivered already gas-sterilised and all were inserted using interrupted everting horizontal mattress sutures. All patients were maintained on oral anticoagulants from day 3.

Five of the 67 patients were operated upon as $\mathbb{\Phi}$ emergencies, three because of acute endocarditis. Thirty-six underwent aortic valve replacement (AVR), $\overrightarrow{\vec{B}}$ 27 men and nine women, ages 32-68 (mean 51). Associated procedures included mitral valvotomy (1) and coronary vein grafts (2). Mitral valve replacement (MVR) was performed on 19 patients, two men and 17 women, ages 4-61 (mean 46). Four had undergone음 previous closed valvotomies and a 4-year-old girl had $\underset{x}{\stackrel{0}{x}}$ acute endocarditis. Four patients had concomitant vein ${ }_{-}^{-}$ grafts. Combined AVR and MVR was carried out on 3 . 11 patients, four men and seven women, ages 31-57. (mean 45), and one had tricuspid valvotomy with Carpentier ring annuloplasty as well. In two of the 11 , the MVR was by a Starr Edwards prosthesis and not윽 a LKPD valve. One further patient who had previously $>$ undergone AVR and MVR with Björk-Shiley pros-Oㅡ. theses had replacement of the leaking aortic valve and $\mathrm{N}$ tricuspid replacement with LKPD valves.

There were five hospital deaths $(7.5 \%)$, none due ton valve failure. Three patients died after AVR, one anN emergency aged 68 in acute left ventricular failure; $\omega$ and one died after MVR (a man of 67 who also had two coronary vein grafts). The patient with previouso AVR and MVR died of jaundice and renal failure following revision AVR and tricuspid replacement.

Sixty-two patients left hospital alive, and follow-up has been $100 \%$ from one to 24 months, giving a totalo of 440 patient-months (which will be increased by October 1977). Average follow-up time so far is seven $\overrightarrow{\mathbb{D}}$ months. There have been five late deaths $(8 \cdot 1 \%)$-two aortics and three mitrals, none valve-related. One 
patient developed SBE nine months after MVR and vein grafts and died following replacement of the detached prosthesis. Only one embolism is known to have occurred (ie, 2 per 1000 patient-months). This was an occlusion of the left renal artery six days after AVR and MVR in a 31-year-old man, whose cardiac rhythm was varying between sinus and atrial fibrillation. Two para-prosthetic leaks have been detected $(2.6 \%)$ and one of these followed MVR in the presence of acute endocarditis. Haemolysis has not been a problem, and all the survivors have shown significant functional improvement.

Fuller details of this two-year continuing experience will be given, but we conclude that LKPD prosthesis, with attractive design features and backed-up by an excellent service from the manufacturers, must currently be regarded as a front-runner in the continuing search for the ideal valve substitute.

\section{Experience with Lillihei-Kaster pivoting disc valve}

M. C. NELIGAN and K. M. SHAW Over a period of twoand-a-half years (December 1974-May 1977) 414 Lillihei-Kaster valves were inserted in 331 patients; most of these were in class 3 or 4 (NYHA). The operative technique utilised was a bubble oxygenator, moderate hemodilution, and hypothermia in the early part of the series, and cold cardio-plegia in the later part of the series. Continuous suture technique of valve insertion was used in almost all cases.

Operative mortality (within 30 days) and late mortality were:

\begin{tabular}{lcccc} 
& Cases & \multicolumn{2}{c}{$\begin{array}{c}\text { Operative } \\
\text { mortality }\end{array}$} & $\begin{array}{c}\% \text { Late } \\
\text { mortality }\end{array}$ \\
Aortic & 145 & 7 & $4 \cdot 8 \%$ & $2 \cdot 9$ \\
Mitral & 110 & 8 & $7 \cdot 3 \%$ & $2 \cdot 7$ \\
Mitral-tricuspid & 12 & 3 & $25.0 \%$ & $8 \cdot 3$ \\
Mitral-aortic & 57 & 6 & $10 \cdot 3 \%$ & $5 \cdot 3$ \\
Triple & 7 & 2 & $28.8 \%$ & 0
\end{tabular}

Follow-up has been almost complete and the complications with the valve prostheses are described.

\section{Comparative analysis of isolated fascia-lata and} homograft aortic valve replacement

A. S. SOORAE, H. O'KANE, and J. ClelAND Thirty-eight consecutive patients who underwent isolated fascia lata aortic valve replacement were compared with a similar series of patients undergoing homograft replacement of the aortic valve. The mean follow-up time was six years in both the groups and all the postoperative survivors were reviewed. The early and long-term results were similar in both the groups, and there was no statistical difference in the operative and late mortality, the incidence of diastolic murmurs (both early and late), valve failure necessitating valve replacement, infective endocarditis, and thromboembolic phenomena.

It is concluded that the long-term results of valve replacement using these two tissues in the aortic position are similar and that there is no place for occasional use of homografts to replace the aortic valve.

\section{Valve replacement in the elderly}

A. H. B. de BONO, B. B. MILSTEIN, and T. A. H. ENGLiSH Valve replacement surgery can now be accomplished with a low operative mortality and with expectation of good symptomatic improvement. Advanced age is not a contraindication to operation, and the restoration of elderly patients to active and independent lives has important social and economic implications. This communication reports our experience with 72 operations in 70 patients aged between 65 and 75 (mean 69.2) years, who had open valve operations between January 1973 and December 1976. This group constitutes $15 \%$ of all patients having valve replacements during this period, the proportion rising from $8 \%$ in 1973 to $24 \%$ in 1976 .

There were 41 aortic valve replacements (one with LV aneurysmectomy and one with replacement of ascending aorta); 26 mitral valve replacements; three mitral and aortic valve replacements; one open mitral valvotomy; and one repair of an aortic paraprosthetic leak. Five patients had previous open intracardiac procedures and five were treated as surgical emergencies. There were three deaths within 30 days of operation (early mortality $4.3 \%$ ) and three patients died three to 10 months after operation. Of the 64 survivors, 57 are assessed as having a good functional result. Two show moderate improvement, and five are not improved.

We conclude that operation should be offered to patients in this age group who present with disabling symptoms and that a good result in terms of independence and enjoyment of normal activities can be anticipated in the majority.

Analysis of results of 1335 closed mitral valvotomies of 10 or more years' follow-up

M. BATES and J. R. BELCHER Thirteen members of the Society decided to pool their entire experience of closed mitral valvotomy performed on patients operated on between 1951 and 1966. These patients were analysed clinically in 1976, giving a minimum follow-up period of 10 years and a maximum of 25 . The patients were in all grades of disability and of all ages, the youngest being $13 \frac{1}{2}$ years and the oldest 67 , but the majority were in the 40-50 age group. The techniques of the operations performed included splitting by finger pressure, and use of the Brock mitral knives and the Tubbs dilator. Individual numbers for the three techniques are not available but the majority of the patients were operated on with the aid of the Tubbs dilator.

An appreciable number of patients were lost to follow-up due to change of address, or country, and although they may have been known to be in good health at eight or nine years, if they could not be examined at 10 years they have not been included in this study.

A total of 2689 primary closed mitral valvotomies were performed by 13 surgeons; 1335 (1095 women and 240 men) survived 10 or more years. It was decided to study six factors which might have an 
adverse affect on the long-term results: (1) age; (2) sex; (3) pre- and early post-operative emboli; (4) calcification in the valve; (5) minimal mitral incompetence; (6) associated aortic valve disease.

Two hundred and two patients had preoperative emboli and 98 early postoperative emboli, but only 30 patients had both, so only 1 in 7 patients with a preoperative embolus are liable to this complication after operation. Age in itself was not considered a contraindication to a satisfactory long-term result as two of the oldest patients, both aged 67 , are alive and well today aged 78. The incidence of valve calcification is greater in men $(33 \%)$ than in women $(16 \%)$, and the percentage of male deaths from a cardiac cause $(20 \%)$ is double that of the female cardiac deaths. The satisfactory long-term clinical result in males with valve calcification $(47 \%)$ is considerably less than in females $(64 \%)$. There is also marked deterioration in the percentage of satisfactory results in males with mitral incompetence $(48 \%)$ compared with females $(61 \%)$. Where associated aortic valve disease is present, this has an adverse effect on the satisfactory results in both sexes-women (54\%), men (59\%).

The overall clinical result after 10 years in both sexes having had one closed mitral valvotomy were as follows:

$\left.\begin{array}{lrr}\text { Dead } & 99 & 10 \cdot 9 \% \\ \text { Poor } & 36 & 3.9 \% \\ \text { Moderate } & 98 & 10.9 \% \\ \text { Satisfactory } & 361 & 39 \% \\ \text { Excellent } & 318 & 35 \%\end{array}\right\} 74 \%$

It was not the intention of this study to analyse the incidence of restenosis and the results of revalvotomy and mitral valve replacements, but the time interval between first and second operations was 9.4 years for men and 8.7 for women. The following patients had revalvotomy or mitral valve replacements and also survived 10 years:

$\begin{array}{llrc} & & \text { Women } & \text { Men } \\ 2 & \text { Revalvotomy } & 202 & 41 \\ 2 & \text { Revalvotomy } & 17 & 6 \\ 3 & \text { Revalvotomy } & 2 & - \\ & \text { MVR } & 162 & 48\end{array}$

It was concluded that closed mitral valvotomy is a good operation with satisfactory long-term results provided there is careful patient selection for the operation.

Valve calcification and minimal mitral incompetence were contraindications certainly in the male patients, and associated aortic valve disease a contraindication in both sexes.

Where a pure stenosis occurred in a young patient without evidence of calcification or incompetence, an open procedure gave no advantage over a closed operation. Closed mitral valvotomy would be of value for many years to come, not only in the developing countries where facilities for open procedures are not yet available.

\section{Cost of a cardiac surgical operation}

K. MORGAN, F. DIDSBURY, and M. BRAIMBRIDGE There are many financial decisions made about cardiac surgery, particularly at the present time, on the assumption that cardiac surgery is much more expensive than any other service in a hospital. There is, however, no accurate evidence relating to the cost of a cardiac operation in Britain today, and a careful costing exercise has been carried out at St. Thomas' Hospital to compare the cost of the average cardiac surgical operation with the cost of a general surgical operation carried out in the same hospital. In fact, an aortic valve replacement was compared with an $\omega$ oesophagectomy.

The figures were arrived at by considering in each $\overrightarrow{\vec{N}}$ instance the fixed patient costs, which included such $\infty$ features as nursing staff, medical staff, hotel services, 음 radiography, pathology, physiotherapy, etc, and the variable costs, which included special factors in the $T$ case of the cardiac surgical patient, like the cost of $\mathbb{D}$ the valve, and the extracorporeal disposables and other special equipment. There were some insignifi- 를 cant variables, such as general medical supplies and equipment, drugs, etc, which were not greatly dissimilar.

While the cost per inpatient day was much more for the cardiac surgical patient the oesophagectomy patient was in hospital much longer ( 24 days against 20). The final comparison was as follows:

$\begin{array}{lcc} & \text { Cardiac } & \text { Oesophagectomy } \\ & £ & £ \\ \text { Fixed costs } & 1596 & 1614 \\ \text { Significant variables } & 780 & - \\ \begin{array}{l}\text { Insignificant variables } \\ \begin{array}{l}\text { On cost for district } \\ \text { headquarters at 3.5\% }\end{array}\end{array} & 286 & 193 \\ \text { Total } & \mathbf{9 3} & 63 \\ & \mathbf{2 7 5 5} & \mathbf{1 8 7 0}\end{array}$

\section{Guest lecture \\ Surgical treatment of coronary heart disease- experience with 9000 operations}

Texas Heart Institute, Houston, Texas, USA

DENTON A. COOLEY

$$
\text { Multistage treadmill evaluation in post aortocoronary }
$$

Multistage treadmill evaluation in post aortocoronary bypass patients

H. O. J. O'KaNe, K. BALNAVE, M. E. SCOTt, P. MORTON,N and J. G. MURTAGH Objectively to assess the results of coronary artery bypass surgery, 15 patients had pre- and post-operative treadmill evaluation, usinge the Bruce protocol; six of these patients also had post- $\mathbb{D}$ operative coronary angiography. There were six: patients with triple saphenous vein grafts (SVG), fouro patients with double SVGs, and five patients witho single SVG. The postoperative treadmill and coronary angiography was carried out four to 13 months after吕 surgery. The exercise parameters looked at were (i) exercise duration; (ii) maximal heart rate; (iii) systolio 
$\mathrm{BP} \times$ heart rate $\times 10^{-2}$ at maximum exercise; (iv) systolic blood pressure at maximum exercise.

Of the six patients who were studied angiographically, four had all their grafts patent, one had two out of three grafts patent, and the sixth had all his grafts blocked.

Twelve patients increased their exercise duration by $2.8 \%$ to $500 \%$ postoperatively with an average increase of $110 \%$. One patient with his single graft patent kept his exercise duration unchanged, and the other two patients dropped their exercise duration by $33 \%$ and $45 \%$. The patient with the $33 \%$ drop was limited by intermittent claudication and the patient with the $45 \%$ drop had his single graft patent.

Fourteen of the 15 patients increased their heart rate at maximum exercise postoperatively by $4.8 \%$ to $67 \%$ with an average increase of $36 \%$ and the 15 th patient dropped his heart rate by $4.0 \%$ although his single graft was patent; the patient with all his grafts blocked increased his heart rate by $43 \%$ at postoperative maximum exercise.

The systolic blood pressure $\times \mathrm{HR} \times 10^{-2}$ rose by $10 \%$ to $93 \%$ in 14 patients with an average rise of $60 \%$ and fell $9 \%$ in the 15 th patient. This latter patient had a single graft to the LAD, which at repeat revisualisation was patent. The two patients with the blocked grafts both increased their product by $9 \%$ and $13 \%$.

The systolic blood pressure at maximum rose by $2 \%$ to $38 \%$ in 13 patients with an average rise of $14 \%$ and fell by $0.9 \%$ and $6 \%$ in two patients. The patient with the $6 \%$ fall had a patent single graft, and the other patient with the $0.9 \%$ fall did not have revisualisation carried out. The single patient, who had all his grafts blocked, raised his systolic blood pressures at maximum exercise by $13 \%$ and the patient with one out of three grafts blocked raised his systolic blood pressure by $9 \%$.

Expanded polytetrafluorethylene as a substitute for saphenous vein in aorto-coronary bypass surgery: early results of a pilot study

R. N. SAPSFORD, H. H. Bentall, W. P. Cleland, J. F. GOODWIN, and C. M. OAKLEY A pilot study, using expanded polytetrafluoroethylene as a substitute for saphenous vein, was carried out because many patients requiring aortocoronary bypass surgery have varicose veins; other patients requiring re-do aortocoronary bypass surgery do not have any saphenous vein left and their arm veins are of ten thrombosed due to previous intravenous therapy; obtaining the long saphenous vein is not without its morbidity, such as haemorrhage, sepsis, sloughing of a skin flap, incorporation of the long saphenous nerve in the scar, and deep venous thrombosis in the leg and troublesome oedema.

Expanded polytetrafluoroethylene (PTFE) is composed of polytetrafluorethylene nodes, interconnected by thin fibrils which are universally porous throughout their length. The fibrils are thin and flexible and allow ingrowth of tissue and capillary formation within the wall of the prosthesis. The material is made into tubular grafts whose internal diameter ranges from
$3 \mathrm{~mm}$ upwards and it is covered with an impervious strengthening outer coat. It has now been in use for approximately two years and it has proved to be as effective as saphenous vein in all sites where it has been used as a substitute.

Twelve patients with triple vessel coronary artery disease were included in the pilot study. Consent was obtained from each patient to allow expanded PTFE to be used as a substitute for saphenous vein to bypass the disease in one of the three vessels requiring grafting. The other two vessels were grafted with saphenous vein. Expanded PTFE was used to graft the right coronary artery in four patients, an anterior descending branch of the left coronary in four patients, and the circumflex branch of the left coronary in four patients. Each patient was restudied at some period between 14 days and three months after the operation. The restudy results for graft patency of both the expanded PTFE graft and the saphenous vein graft are presented.

Expanded PTFE was used as the only graft material in an additional group of five patients who required a total of eight grafts. The material was used in these patients because they had no suitable veins at all. Early restudies were carried out and the graft patency rate in this group will be presented as well.

An evaluation of this material was thought desirable because, if it proves to be as good as saphenous vein, it could have an important part to play in aortocoronary bypass surgery.

Comparisons of haemodynamic effectiveness of an intracorporeal abdominal left ventricular assist device (ALVAD) and intraaortic balloon pumping (IABP) in man*

J. GREAME BENNETT and JOHN C. NORMAN Intracorporeal (abdominal) left ventricular assist devices have been approved by NHLBI auspices for initial clinical trials in our institution. Over the last six months, trials in preterminal post-cardiotomy patients (lasting from 1 to 140 hours) have been undertaken during carefully prescribed conditions and protocols.

During the course of concurrent ALVAD and IABP support, six days after implantation of the former, we have compared the haemodynamic effectiveness of these two modalities of circulatory support, ie:

\begin{tabular}{lrrr}
$N=8$ & Control & \multicolumn{1}{c}{ IABP } & \multicolumn{1}{c}{ ALVAD } \\
C.I. $\left(1 / \mathrm{min} / \mathrm{m}^{2}\right)$ & 1.49 & $1.56(+5 \%)$ & $2.01(+35 \%)$ \\
PCW $(\mathrm{mmHg})$ & 20 & $19(-5 \%)$ & $14(-30 \%)$ \\
AoP $(\mathrm{mmHg})$ & 68 & $69(+1 \%)$ & $85(+25 \%)$ \\
SVR (dyne-sec-cm & & & \\
& 2098 & $2020(-4 \%)$ & $1936(-8 \%)$
\end{tabular}

This abdominal left ventricular assist device is seven times more effective that IABP in increasing AoP and $C I \quad(P<0.01)$ and six times more effective in decreasing PCW $(P<0.01)$. SVR is also significantly reduced from control values $(P<0 \cdot 01)$.

*Norman, JC-Hemodynamic effects of ALVAD pumping in Man: Topical Report to NHLBI, Contract \#NO1-HV-5-3006, July 28, 1976. 
Investigations into nutritional status of cardiac surgical patients

R. K. Walesby, A. W. GoOde, and H. H. Bentall Nutritional studies were carried out on 10 randomly selected cardiac surgery patients undergoing valve replacements. Measurement of the body cell mass (the energy-utilising component of the body and hence the most accurate index of nutritional status) was determined non-invasively from total body potassium measured preoperatively and on the seventh postoperative day was $10.4 \mathrm{~g}$ nitrogen/day (range 1.96-18.8), thereby confirming that conventional nitrogen balance methods did not adequately quantitate the metabolic load of surgery.

Despite adequate medical management, with no clinical signs of over-hydration, the total body water measured preoperatively showed a mean overhydration of $11.4 \%$ (range $4-30 \%$ ) when compared with that predicted from tables based on body surface area $(P<0 \cdot 05)$. However, there was no signifcant difference between pre- and post-operative body water measured on the seventh day $(P>0.7)$.

Four of the patients exhibited preoperative nutritional depletion of $17 \cdot 2 \%$ (range $13-30 \%$ ), as assessed by loss of body cell mass from total body potassium measurements. The depleted group had a significantly longer mean postoperative hospital stay of 29.8 days (range 19-59) when compared with that of the well-nourished patients' 16 days (range 14-19). In patients with a normal packed cell volume and clinically free from oedema there is a highly significant correlation between body cell mass measured by total body potassium and fat-free mass measured anthropometrically using skinfold calipers $(P<0.005)$. This may allow a single bedside assessment of the degree of preoperative nutritional depletion, as clinical impressions of nutritional depletion in each patient were poor.

Variations in blood glucose concentration in openheart operations and their significance

J. R. KEATES, C. v. TOMKINS, and P. A. SONKSEN It has long been known that in haemorrhagic shock, trauma, and heart failure there are disturbances of glucose metabolism. Open-heart operations are no exception. Previous investigations in patients have usually been complicated by the use of a glucose pump prime, and no firm conclusions have been reached as to the mechanism of the changes.

In this series, 50 patients have been studied during the operative period. Observations have been made of blood glucose, potassium, insulin, growth hormone, cortisol, glucagon, noradrenaline, and adrenaline.

In 13 patients, intravenous glucose tolerance tests were performed before and after operation. A Ringerlactate prime was used, and operations were performed at $32^{\circ}$ and $37^{\circ} \mathrm{C}$.

Marked hyperglycaemia not explicable by glucose administration was noted during the perfusion with depression of insulin levels and without a marked rise in growth hormone levels. There was no significant difference between hypothermic patients and normothermic patients in glucose rise, insulin fall, $\stackrel{\vec{\rho}}{\stackrel{5}{\circ}}$ glucagon, catecholamines, or cortisol levels. There was no correlation between glucose and catechola- $\underline{\underline{D}}$ mine or glucagon levels. After perfusion the glucose $\frac{\bar{\rho}}{\square}$ level falls steadily despite blood transfusion. This is $\mathbb{\mathbb { D }}$ associated with an insulin rebound and may account for some of the hypokalaemia seen at this time.

After operation there is a marked insulin resistance $\overrightarrow{0}$ associated with a paradoxical growth hormone response to intravenous glucose. In patients with low $\vec{\omega}$

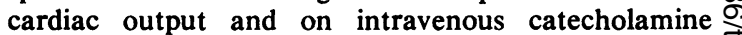
infusion high insulin and glucose levels were seen. In $\overrightarrow{\vec{x}}$ these patients, who are insulin-resistant, there may be a case for insulin infusions to be used therapeutically. $\omega$

No patient suffered hypoglycaemia in the absence of added glucose solutions.

\section{Effect of pulsatile flow on cortisol secretion during cardiopulmonary bypass}

K. M. TAYLOR, GILliaN S. WRIGHT, W. H. BAIN, P. K. O을 CAVES, J. S. REID, M. S. WALKER, W. MCNAB, and $\frac{c}{2}$ MARGARET M. HUTTON We have previously reported the occurrence of impaired cortisol secretion during $\overrightarrow{0}$ non-pulsatile cardiopulmonary bypass (CPB) (Taylor $\infty$ et al., 1976). The effect of pulsatile flow during the period of extracorporeal circulation (ECC) has been studied using a modified roller pump (Stockert Pulsatile Pump-Munich) in 10 consecutive patients submitted to elective open-heart surgical procedure (pulsatile group).

Standard non-pulsatile flow during ECC was $\varrho$ employed in a control group of 10 patients (nonpulsatile group). There was no significant differ- 3 ence in mean age, weight, bypass time, mean pump flow or mean arterial blood pressure during ECC between pulsatile and non-pulsatile groups. Serial blood samples were obtained for total plasma cortisol, packed cell volume, and plasma-free haemoglobin $\underset{x}{\stackrel{\nu}{0}}$ in all patients. In the non-pulsatile group, there was reduced cortisol secretion during the period of ECC, 3 . as previously reported (end-ECC cortisol $=612 \mathrm{nmol} / 1$. \pm 34 SEM), with the restoration of cortisol secretion 윽 in the post-ECC period. By contrast, in the pulsatile group, cortisol levels rose significantly during the $\frac{}{3}$ period of ECC, indicating continued adrenal secretion $D$ of cortisol (end-ECC cortisol $=842 \mathrm{nmol} / \mathrm{l} \pm 46 \mathrm{SEM}$ 을. ( $P<0.001$ cf. controls).

The mean rise in plasma-free haemoglobin from start o to end of ECC was $69 \cdot 7 \pm 16.2$ SEM in the non- N pulsatile group and $43.2 \mathrm{mg} / \mathrm{dl} \pm 5.5 \mathrm{SEM}$ in the pulsatile group $(t=1.55 \mathrm{NS})$. This clearly indicates $\omega$ that the use of pulsatile flow was not associated with increased red blood cell destruction.

These studies demonstrate that the suppression of $\mathbb{D}$ adrenal cortisol secretion, which occurs during non- $\stackrel{+}{+}$ pulsatile ECC, does not occur when pulsatile flow 0 is used.

\section{Reference}

Taylor, K. M., Jones, J. V., Walker, M. S., Rao, L. G. S., and Bain, W. H. (1976). Circulation, 54, 20.

\section{,}

